\title{
НАСКОЛЬКО ЧАСТО ВСТРЕЧАЕТСЯ ТОКСИЧНОСТЬ ВИТАМИНА D? ДАННЫЕ НАЦИОНАЛЬНОГО ОПРОСА ЭНДОКРИНОЛОГОВ РОССИИ
}

\author{
Катамадзе Н.Н., Пигарова Е.А., Поваляева А.А., Жуков А.Ю., Глазьева В.С., Дзеранова Л.К., Рожинская Л.Я., \\ Марова Е.И., Беловалова И.М., Дедов И.И.
}

ФГБУ «НМИЦ эндокринологии» Минздрава России, Москва, Россия

В 2014 г. Российской ассоциацией эндокринологов были разработаны и внедрены в клиническую практику рекомендации по профилактике и лечению дефицита витамина D у взрослых. Несмотря на то что назначение витамина $\mathrm{D}$ имеет важное значение для здоровья человека, в некоторых случаях передозировка витамина $\mathrm{D}$ может сопровождаться его токсичностью, которая имеет разнообразные клинические проявления и может приводить к негативным последствиям для здоровья.

ЦЕЛЬ: оценить частоту встречаемости и определить особенности токсичности витамина D в условиях реальной клинической практики.

МАТЕРИАЛЫ И МЕТОДЫ: В Январе 2021 г. в национальном опросе приняли участие 710 специалистов в области здравоохранения. 79\% респондентов составили эндокринологи, а 21\% участников опроса врачи других областей клинической медицины. 94\% опрошенных составили и женщины, причем все возрастные группы от 20 и до 65 лет и старше были представлены практически поровну.

PEЗУЛЬтАТЫ: по результатам опроса, 16,3\% врачей сталкивались с токсичностью витамина D: 42\% один раз, 25,2\% - дважды, 21\% - три раза, 11,8\% сообщили о четырех или более случаях в своей клинической практике. Наиболее распространенными причинами токсичности витамина D было потребление увеличенных доз колекальциферола, инициированное пациентом (58,3\%) или врачом (36\%), а также потребление активных метаболитов витамина D (24\%). Несколько реже врачи наблюдали передозировку в связи с неточностью в концентрации препарата, указанной производителем (фактическая концентрация была выше заявленной) - в 22,3\%. Реже всего врачи сталкивались с передозировкой в исходе генетического дефекта СYРА241 (11,4\%), гранулематозных (саркоидоз, гистиоцитоз, туберкулез и т.д.) (8\%) или лимфопролиферативных заболеваний (4,6\%). Около 70\% врачей выполняют оценку кальция в крови наряду с 25(OH)D. 77,2\% также оценивают уровень паратиреоидного гормона и 24\% - уровень кальция в суточной моче.

ВЫВодЫ: эндокринологи часто сталкиваются с передозировкой витамина D. Особое внимание следует уделять назначению высоких доз нативных форм витамина D или активных метаболитов/аналогов витамина D без регулярного мониторинга параметров кальций-фосфорного обмена, а также в случаях, когда пациенты принимают их самостоятельно. 